\title{
Inhibitory modulation of the cough reflex by acetylcholine in the caudal nucleus tractus solitarii of the rabbit
}

\author{
Elenia Cinelli ${ }^{1}$, Ludovica Iovino ${ }^{1}$, Fulvia Bongianni, Tito Pantaleo, Donatella Mutolo* \\ Dipartimento di Medicina Sperimentale e Clinica, Sezione Scienze Fisiologiche, Università degli Studi di Firenze, Viale G.B. Morgagni 63, 50134 Firenze, Italy
}

\section{A R T I C L E I N F O}

\section{Keywords:}

Acetylcholine receptors

Scopolamine

Cough reflex

Nucleus tractus solitarii

Control of breathing

\begin{abstract}
A B S T R A C T
A cholinergic system has been described in the nucleus tractus solitarii (NTS). However, no information is available on the role played by acetylcholine (ACh) in the modulation of the cough reflex within the caudal NTS that has an important function in cough regulation. We addressed this issue making use of bilateral microinjections $(30-50 \mathrm{nl})$ of $10 \mathrm{mM}$ ACh combined with $5 \mathrm{mM}$ physostigmine as well as of $10 \mathrm{mM}$ mecamylamine or $10 \mathrm{mM}$ scopolamine into the caudal NTS of pentobarbital sodium-anesthetized, spontaneously breathing rabbits. Microinjections of ACh/physostigmine caused depressant effects on the cough reflex induced by mechanical and chemical stimulation of the tracheobronchial tree. They also elicited transient increases in respiratory frequency and decreases in abdominal activity. These effects were prevented by scopolamine, but not by mecamylamine. The results show for the first time that ACh exerts an inhibitory modulation of the cough reflex through muscarinic receptors within the caudal NTS. They also may provide hints for novel antitussive approaches.
\end{abstract}

\section{Introduction}

Cough is one of the most important defensive reflex brought into action by actually or potentially damaging events applied to the airways (Korpáš and Tomori, 1979). Peripheral and central mechanisms underlying nociception and cough share similar features; neuroactive agents involved in the central control of pain sensation (Millan, 2002; Yan et al., 2017) and concomitant reflex responses play a role also in the downregulation of the cough reflex (see Mutolo, 2017 also for further Refs. Mutolo et al., 2008, 2012, 2014; Cinelli et al., 2013, 2016).

Several brainstem areas appear to contribute to the generation and regulation of cough responses in mammals (e.g. Gestreau et al., 1997; Bongianni et al., 1998; Jakus et al., 2008; Mutolo et al., 2002b; Poliacek et al., 2004, 2005, 2014; Shannon et al., 2004; Simera et al., 2013; see also Mutolo, 2017). Recent findings obtained mainly in the rabbit (for review see Mutolo, 2017) have led to the proposal that two medullary structures play a prominent role in the control of cough reflex responses and are sites of action of antitussive or protussive drugs, i.e. the caudal nucleus tractus solitarii (NTS), the first relay medullary station of the cough reflex pathway, and the caudal ventral respiratory group (cVRG), where neurons responsible for the expiratory component of the reflex are located (for the role of the cVRG see also Poliacek et al., 2007, 2010, 2015). Of note, afferent inputs from peripheral chemoreceptors and pulmonary rapidly adapting receptors converge on neurons of the caudal NTS (Mifflin et al., 1988; Mifflin, 1992; Machado, 2001; Kubin et al., 2006). However, recently evidence has been provided of the existence in the cat of important control mechanisms within the rostral NTS (Poliacek et al., 2017a,b; for review see Mutolo, 2017) very similar to those described for the caudal NTS in the rabbit. This could be possibly related to marked differences in the animal species.

Besides its modulatory quality, acetylcholine (ACh) also acts as one of the most prominent neurotransmitters in the peripheral and central nervous system. Interestingly, cholinergic transmission profoundly affects the perception of pain via both nicotinic (nAChRs) and muscarinic (mAChRs) receptors (for review see Naser and Kuner, 2017). There is considerable direct and indirect evidence that ACh is widely distributed in the region of NTS (Kobayashi et al., 1978; Criscione et al., 1983; Ernsberger et al., 1988; Ruggiero et al., 1990; Zoccal et al., 2014) where both mAChRs and nAChRs are present. Muscarinic receptors are located in more caudal regions, including the commissural subnucleus, while nicotinic receptors are predominantly located at more rostral levels, i.e. in the medial, ventrolateral and ventral subnuclei (Maley, 1996; see also Furuya et al., 2014).

ACh contributes to autonomic regulation. In particular, it is involved in the regulation of both cardiovascular (e.g. Shihara et al., 1999; Furuya et al., 2014, 2017; Zoccal et al., 2014) and respiratory activity (e.g. Haxhiu et al., 1984; Bianchi et al., 1995; Shao and

\footnotetext{
* Corresponding author.

E-mail address: donatella.mutolo@unifi.it (D. Mutolo).

${ }^{1}$ These authors contributed equally to this work.
} 
Feldman, 2000, 2001, 2002, 2009; Shao et al., 2008; Boutin et al., 2017) through both nAChRs and mAChRs. However, only scanty knowledge is available on its contribution to the modulation of the cough motor pattern. Recently, it has been shown that (-)-nicotine administered via brainstem circulation or directly applied to the cVRG causes mecamylamine-insensitive inhibitory effects on mechanicallyinduced cough (Poliacek et al., 2015). In the present research, the possible role of ACh in the modulation of the cough reflex at the level of the caudal NTS of pentobarbital sodium-anesthetized, spontaneously breathing rabbits was investigated making use of microinjection techniques.

\section{Materials and methods}

\subsection{Ethical approval}

Animal care and experimental procedures were conducted in accordance with the Italian legislation and the official regulations of the European Community Council on the use of laboratory animals (Decreto Legislativo 4/3/2014 no. 26 and Directive 2010/63/UE). The study was approved by the Animal Care and Use Committee of the University of Florence. All efforts were made to minimize both the number of animals used and their suffering. Details about the methods employed have been described in our previous studies on the NTS region and will be concisely reported here (Cinelli et al., 2013, 2016; Mutolo et al., 2007, 2008, 2009, 2012, 2014; Mutolo, 2017).

\subsection{Animal preparation and recording procedures}

Experiments were carried out on 15 male New Zealand White rabbits $(2.7-3.3 \mathrm{~kg}$ ) anesthetized with pentobarbital sodium $(40 \mathrm{mg} / \mathrm{kg}$ i.v., supplemented by $2-4 \mathrm{mg} / \mathrm{kg}$ every $30 \mathrm{~min}$; Sigma-Aldrich, St. Louis, MO, USA). Atropine $(0.15 \mathrm{mg} / \mathrm{kg}$ i.m.) was administered to reduce mucosal secretion in the airways. The adequacy of anesthesia was assessed by the absence of reflex withdrawal of the hindlimb in response to noxious pinching of the hindpaw. Additional criteria were the presence of a stable and regular pattern of phrenic bursts and the absence of fluctuations in arterial blood pressure. The trachea was cannulated and polyethylene catheters were inserted into a femoral artery and vein for monitoring arterial blood pressure and drug delivery, respectively. The $\mathrm{C}_{3}$ or $\mathrm{C}_{5}$ phrenic root on one side was prepared for recordings. The animal was placed in a prone position and fixed by a stereotaxic head holder and vertebral clamps. The head was ventroflexed for optimal exposure of the dorsal surface of the medulla by occipital craniotomy. Body temperature was maintained at $38.5-39^{\circ} \mathrm{C}$ by a heating blanket controlled by a rectal thermistor probe.

Efferent phrenic nerve activity was recorded with bipolar platinum electrodes. Abdominal muscle electromyographic (EMG) activity was recorded by wire electrodes. Phrenic and abdominal activities were amplified, full-wave rectified, and "integrated" (low-pass RC filter, time constant $100 \mathrm{~ms}$ ). Arterial blood pressure was recorded by a straingauge manometer and end-tidal $\mathrm{CO}_{2}$ partial pressure by an infrared $\mathrm{CO}_{2}$ analyzer (Capnocheck Plus, Smiths Medical PM, Waukesha, WI, USA). Cardiorespiratory variables were analyzed using a personal computer, supplied with an appropriate interface (Digidata 1440, Molecular Devices, Sunnyvale, CA, USA) and software (Axoscope, Molecular Devices).

\subsection{Microinjection procedures}

Bilateral microinjections were performed at two different sites along the rostrocaudal extent of the caudal NTS. The first was at the level of the caudal-most end of the area postrema that approximately corresponds to the opening of the central canal of the IV ventricle, $0.6-0.8 \mathrm{~mm}$ lateral to the midline and $0.7-0.8 \mathrm{~mm}$ below the dorsal medullary surface. The second was $0.5 \mathrm{~mm}$ more caudal, $0.4-0.5 \mathrm{~mm}$ lateral to the midline and $0.7-0.8 \mathrm{~mm}$ below the dorsal medullary surface. Owing to the spread of the 50 nl-injectate, $<400 \mu \mathrm{m}$ in any direction (for the spread of the injectate see also Results and Discussion), injections at the first sites affected a NTS area probably including the most caudal extent of the medial subnucleus (see Mutolo et al., 2007). The stereotaxic coordinates were selected according to the atlas of Meessen and Olszewski (1949).

Microinjections (30-50 nl) were performed as described in our previous reports via a single-barrel glass micropipette (tip diameter $10-25 \mu \mathrm{m}$ ). The volume of the injectate was measured directly by monitoring the movement of the fluid meniscus in the pipette barrel with a dissecting microscope equipped with a fine reticule. The following drugs were used: $10 \mathrm{mM}$ ACh chloride (endogenous neurotransmitter at cholinergic synapse; Sigma-Aldrich), $5 \mathrm{mM}$ physostigmine salycilate (an acetylcholinesterase inhibitor; Sigma-Aldrich), $10 \mathrm{mM}$ mecamylamine hydrochloride (a noncompetitive nAChR antagonist; Sigma-Aldrich), $10 \mathrm{mM}$ (-)-scopolamine hydrobromide trihydrate (a nonselective mAChR antagonist; Sigma-Aldrich). Each drug was dissolved in $0.9 \% \mathrm{NaCl}$ solution. Drug concentrations were in the same range as those previously used in in vivo preparations (e.g. Furuya et al., 2014; Zhang et al., 2016; Boutin et al., 2017). ACh at $10 \mathrm{mM}$ was injected in combination with $5 \mathrm{mM}$ physostigmine to obtain relative more pronounced and lasting effects. Control injections of equal volumes of the vehicle solution at the responsive sites were also performed. Fig. 1 illustrates the localization of injection sites that was confirmed in some preparations by injecting green fluorescent latex microspheres (LumaFluor, New City, NY, USA) added to the drug solution (three for ACh/physostigmine and two for scopolamine).

\subsection{Stimulation procedures}

Mechanical stimulation was delivered by a custom-built device recently described and validated (Mutolo et al., 2014) using a 0.5-mm diameter nylon fibre with a smoothed tip inserted through a lateral port of the tracheal cannula. The device allowed to set the number of forth and back movements or cycles (1-3 cycles), shaft velocity (10-20 mm/ s), and shaft displacement (10-20 mm). Mechanical stimulation was set at 1 cycle, $15 \mathrm{~mm} / \mathrm{s}$ velocity, and $15 \mathrm{~mm}$ displacement to produce a bout of 2-4 coughs. The stimulation protocol comprised three stimulation trials performed in succession (at 1-2 min interval) before drug administration, repeated $\sim 5 \mathrm{~min}$ after the completion of all the microinjections and at appropriate intervals (at least $5 \mathrm{~min}$ ) to follow the recovery process for a maximum of $90 \mathrm{~min}$.

Chemical stimulation of the tracheobronchial tree was performed by means of citric acid inhalation (for details see Mutolo et al., 2009). Citric acid (1 M, Sigma-Aldrich) was freshly dissolved in $0.9 \% \mathrm{NaCl}$ solution and nebulized. The opening of the tracheal cannula, through which the rabbits were spontaneously breathing, was exposed to a steady stream of the nebulized citric acid solution for $\sim 3 \mathrm{~s}$. Chemical stimulation was always applied 2-3 min after mechanically-induced cough and caused a bout of several coughs usually immediately followed by a tachypneic response. As a rule, chemical stimulation was performed both before and $\sim 10 \mathrm{~min}$ after the completion of the injections and repeated at appropriate intervals $(\geq 10 \mathrm{~min}$ ) to follow the recovery process.

\subsection{Histology}

The histological control of pipette tracks and injection sites was performed as previously described (for details, see Mutolo et al., 2007, 2012; Cinelli et al., 2016). Frozen $20-\mu \mathrm{m}$ coronal sections stained with Cresyl Violet were used. Coronal sections of the medulla in which injection sites were marked by fluorescent microspheres were examined in a light and epifluorescence microscopy (Eclipse E400, Nikon, Japan) equipped with the Nikon Intensilight C-HGFI mercury-fibre illuminator. A Nikon DS-Fi1digital camera was used to take photomicrographs. 


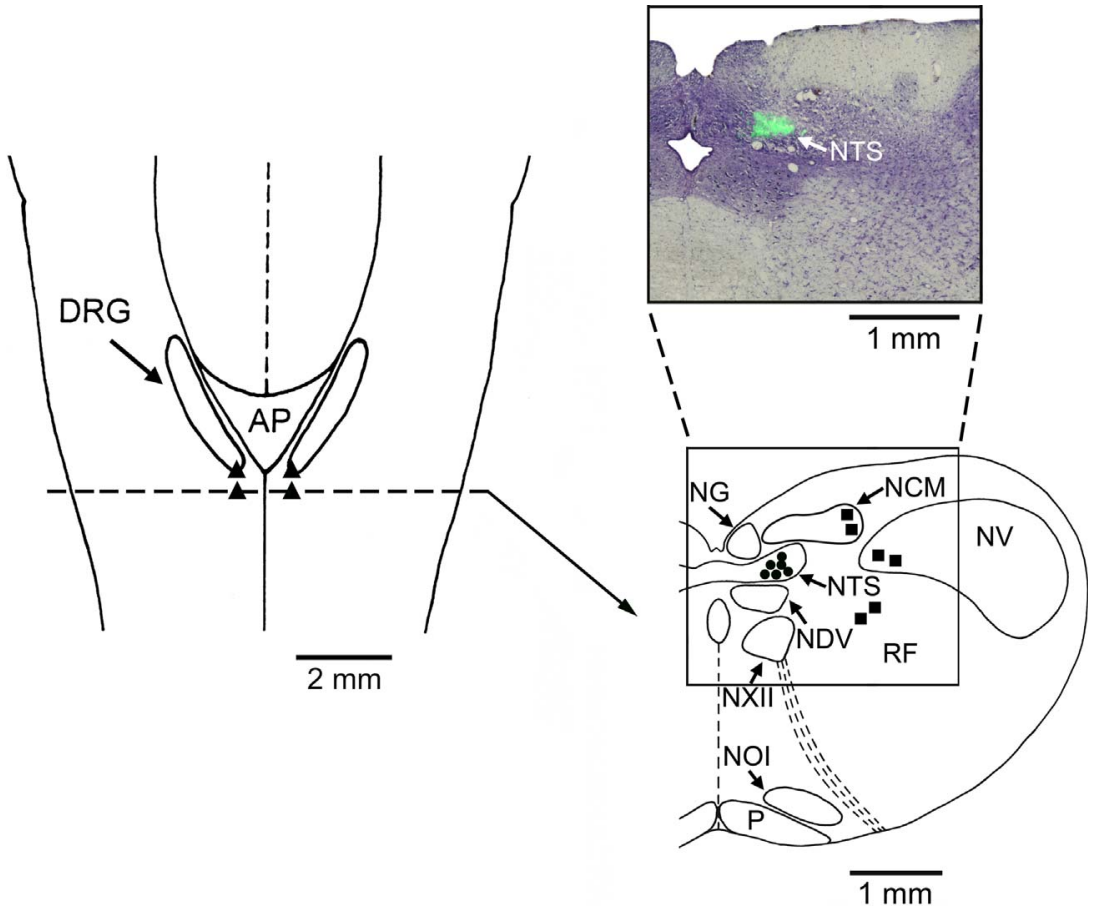

Fig. 1. Localization of injection sites and histological control. Left: diagrammatic representation of the dorsal view of the medulla oblongata of the rabbit showing the sites where bilateral microinjections ( $\mathbf{\Delta}$ ) of different drugs have been performed into the caudal nucleus tractus solitarii. AP, area postrema; DRG, dorsal respiratory group. Right: schematic representation of a coronal section of the medulla oblongata at the level indicated in the left panel (dashed line) showing the location of representative sites ( ) where acetylcholine/physostigmine microinjections were performed. Only control injection sites ( $\square$ ) that could be projected on the schematic coronal section of the medulla oblongata have been reported. NCM, nucleus cuneatus medialis; NDV, nucleus dorsalis nervi vagi; NG, nucleus gracilis; NOI, nucleus olivaris inferior; NTS, nucleus tractus solitarii; NV, nucleus tractus spinalis nervi trigemini; NXII; nucleus nervi hypoglossi; P, tractus piramidalis; RF, reticular formation. The atlas of Meessen and Olszewski (1949) and the atlas of Shek et al. (1986) were used for comparison. An example of the location of fluorescent beads microinjected into the caudal NTS (green) is reported in the photomicrograph displaying a histological image corresponding to the rectangular area outlined on the diagram of the coronal section. The histological section is counterstained with Cresyl Violet. Light-field and fluorescent photomicrographs have been superimposed.
Illustrations were prepared in Adobe Photoshop CS3 (Adobe Systems Incorporated, San Jose, CA, USA).

\subsection{Data collection and analysis}

Respiratory variables were measured during eupneic breathing and reflex responses (Mutolo et al., 2014; see also Poliacek et al., 2011, 2017a). The inspiratory $\left(T_{I}\right)$ and expiratory $\left(T_{E}\right)$ times, as well as the total duration of the respiratory cycle $\left(\mathrm{T}_{\mathrm{T}}\right)$ were measured. The respiratory frequency was subsequently calculated (breaths/min). Peak amplitude (arbitrary units) of the phrenic nerve activity and abdominal EMG activity were measured on integrated traces. They were normalized by expressing them as a fraction (or percentage) of the highest achievable amplitude observed in each animal (relative units, RU). Breathing pattern variables were measured for an average of five consecutive breaths prior to and following drug microinjections. Furthermore, systolic and diastolic blood pressures were measured at $2 \mathrm{~s}$ intervals and mean arterial pressure was calculated as the diastolic pressure plus one-third of the pulse pressure. The measurement periods of cardiorespiratory variables were the same selected for cough-related variables (see below). Owing to the small variations in respiratory and cardiovascular variables within each measurement period, average values were taken as single measurements for the purpose of analysis.

The cough motor pattern in response to mechanical or chemical stimulation of the tracheobronchial tree is characterized by repeated coughs. Cough-related variables included the cough-related $\mathrm{T}_{\mathrm{T}}, \mathrm{T}_{\mathrm{I}}$ and $\mathrm{T}_{\mathrm{E}}$, peak phrenic amplitude (RU), peak abdominal activity (RU) and the cough number, i.e. the number of coughs following each stimulation.
The cough $\mathrm{T}_{\mathrm{I}}$ was defined as the interval from the onset of phrenic activity to its peak activity. The cough $\mathrm{T}_{\mathrm{E}}$ was defined as the interval from peak phrenic amplitude to the onset of the subsequent phrenic burst. Cough-related variables were measured and averaged before and after drug administration at the time when the maximum response and the complete recovery were observed (three trials for mechanical stimulation and a single trial for citric acid inhalation). The average values of cough-related variables were taken as single measurements for subsequent statistical analysis (GraphPad Prism 5, GraphPad Software, Inc., La Jolla, CA, USA). An expiration reflex could occur as the first motor event in a cough epoch (Korpáš and Tomori, 1979; Widdicombe and Fontana, 2006; for further details and comments see Refs. Mutolo et al., 2007, 2008, 2009, 2012; Tatar et al., 2008; Cinelli et al., 2013). Expiration reflexes were not considered for data analysis. Comparisons were performed by using one-way repeated-measures ANOVA followed by Student-Newman-Keuls tests. Paired $t$-tests were also used when appropriate. Reported values are means \pm SEM; $P<0.05$ was taken as significant.

\section{Results}

Bilateral microinjections $(n=6)$ of $10 \mathrm{mM}$ ACh $(300-500$ pmol) and $5 \mathrm{mM}$ physostigmine $(150-250 \mathrm{pmol})$ at the two selected caudal NTS sites caused within $1 \mathrm{~min}$ significant increases in respiratory frequency (from $54.5 \pm 1.7$ to $70.9 \pm 4.1$ breaths $/ \mathrm{min} ;+30.8 \pm 7.0 \%$; $P<0.001)$ that faded out within $5 \mathrm{~min}$. No significant changes in mean arterial pressure occurred (Table 1). These effects were accompanied by decreases or even complete suppression of expiratory activity

Table 1

Cardiorespiratory variables during eupneic breathing before and $\sim 3 \mathrm{~min}$ after bilateral microinjections of $10 \mathrm{mM}$ acetylcholine/5 mM physostigmine ( $=6$ ) into the caudal NTS.

\begin{tabular}{|c|c|c|c|c|c|c|}
\hline & $\mathrm{T}_{\mathrm{T}}, \mathrm{s}$ & $\mathrm{T}_{\mathrm{I}}, \mathrm{s}$ & $\mathrm{T}_{\mathrm{E}}, \mathrm{s}$ & PPA, RU & PAA, RU & $\mathrm{MAP}, \mathrm{mmHg}$ \\
\hline Control & $1.10 \pm 0.04$ & $0.37 \pm 0.01$ & $0.73 \pm 0.03$ & $0.53 \pm 0.01$ & $0.06 \pm 0.01$ & $98.3 \pm 4.7$ \\
\hline ACh/Physo & $0.86 \pm 0.06^{* .20 k}$ & $0.36 \pm 0.02$ & $0.52 \pm 0.05^{* \ldots * * *}$ & $0.55 \pm 0.03$ & $0.03 \pm 0.01^{* * * *}$ & $97.3 \pm 5.4$ \\
\hline Recovery & $1.09 \pm 0.03$ & $0.36 \pm 0.01$ & $0.73 \pm 0.02$ & $0.54 \pm 0.01$ & $0.07 \pm 0.01$ & $98.4 \pm 5.1$ \\
\hline
\end{tabular}

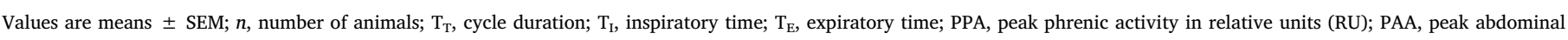
activity in relative units (RU); MAP, mean arterial blood pressure.

*** $P<0.001$, compared with controls as well as with recovery. 


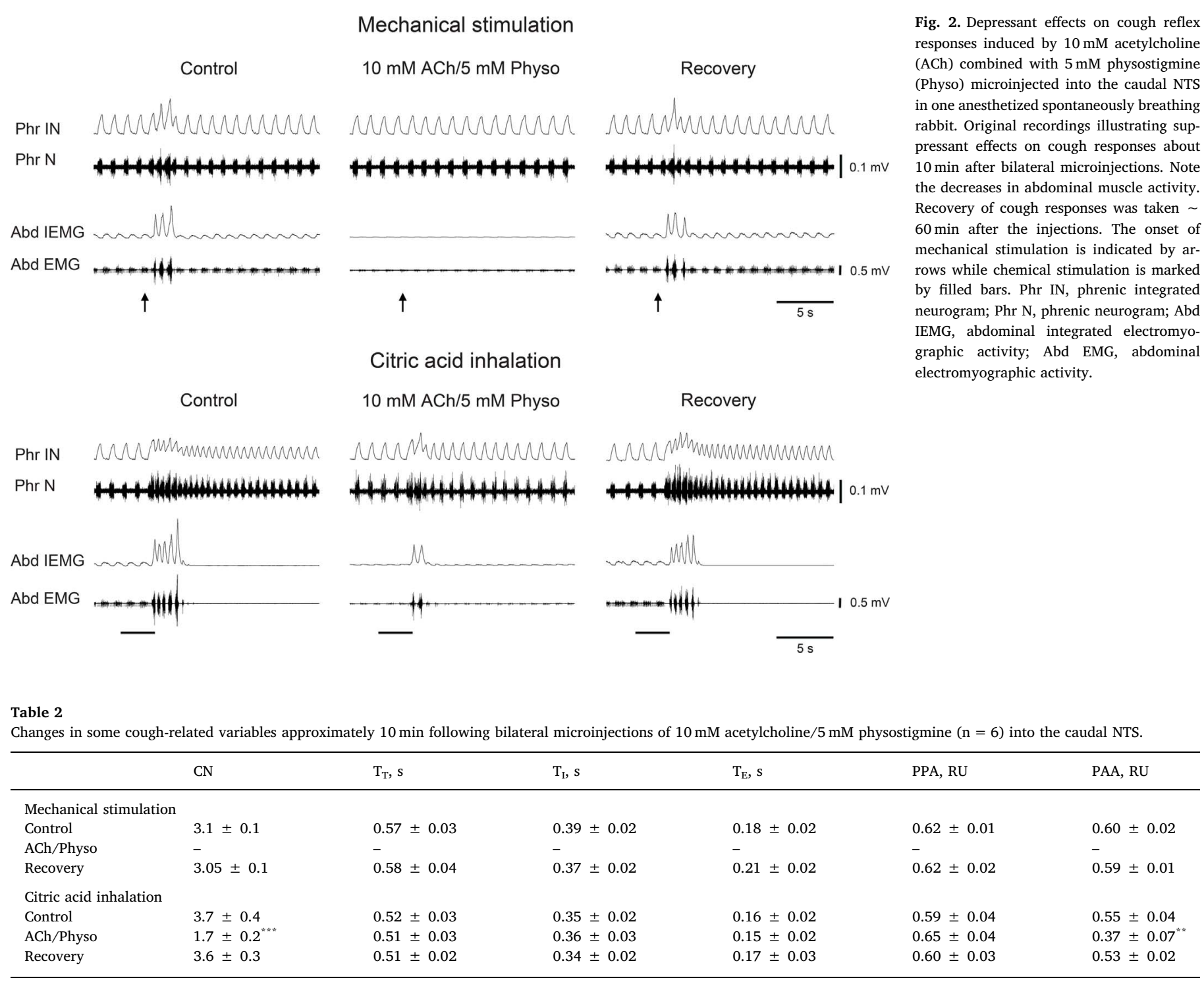

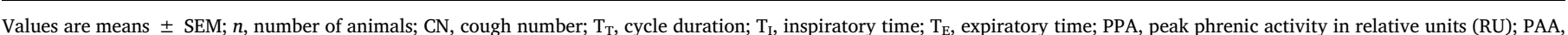
peak abdominal activity in relative units (RU); -, cough response absent.

${ }^{* * *} P<0.01,{ }^{* * * *} P<0.001$, compared with control cough as well as with recovery.

that persisted for longer time period (10-15 $\mathrm{min}$ ) and recovered within $30 \mathrm{~min}$. Progressive depressant effects on the cough reflex reached a maximum within $10 \mathrm{~min}$. At that time cough responses induced by mechanical stimulation of the tracheobronchial tree were completely abolished, while citric acid inhalation-induced cough responses were only strongly reduced both in the cough number and in the peak abdominal amplitude (see Fig. 2 and Table 2). Cough-related variables resumed control values within $60 \mathrm{~min}$.

To disclose whether ACh exerts its effects through nAChRs or mAChRs, the corresponding specific antagonists were employed. We injected $10 \mathrm{mM}$ mecamylamine $(n=3 ; 300-500 \mathrm{pmol})$ or $10 \mathrm{mM}$ scopolamine $(n=4 ; 300-500 \mathrm{pmol})$ and after an interval of $\sim 5 \mathrm{~min}$ $10 \mathrm{mM}$ ACh $/ 5 \mathrm{mM}$ physostigmine into the same sites. Neither mecamylamine nor scopolamine caused obvious and significant effects on baseline respiratory activity (paired $t$-tests). Indeed, in both cases respiratory frequency remained fairly constant with variations lower than $\pm 1 \%$ in each preparation. ACh-induced changes in baseline respiratory activity as well as in the cough reflex were not counteracted by mecamylamine, but were prevented by scopolamine (not shown).

In two additional preparations, bilateral control microinjections of $10 \mathrm{mM} \mathrm{ACh} / 5 \mathrm{mM}$ physostigmine were performed at different medullary locations ( 4 trials) sufficiently far $(>0.8 \mathrm{~mm}$ ) from the responsive sites (see e.g. Nicholson, 1985; Lipski et al., 1988; Mutolo et al., 2007, 2012, 2014; Sykova and Nicholson, 2008; Cinelli et al., 2013, 2016). With respect to the responsive sites, they were performed into the NTS region $1 \mathrm{~mm}$ rostral and $1 \mathrm{~mm}$ lateral to the midline $(1$ trial), into the adjacent reticular formation (2 trials) and into the reticular formation located $1 \mathrm{~mm}$ more caudal at the same depth (1 trial). Control microinjections ( 2 trials for each location) were also performed into the nucleus cuneatus medialis and the nucleus tractus spinalis nervi trigemini. All these microinjections failed to induce changes in the breathing pattern as well as suppressant effects on the cough reflex. Control injections of equal volumes of the vehicle solution at the responsive sites performed in 3 preparations before drug administration were ineffective. The localization of injection sites was confirmed by the histological control of pipette tracks and the location of fluorescent beads. The localization of injection sites on a dorsal view of the medulla oblongata along with the distribution of injection sites within the caudal NTS and some control regions is reported in Fig. 1. Only the distribution of sites where $10 \mathrm{mM} \mathrm{ACh} / 5 \mathrm{mM}$ physostigmine were injected has been reported. The same figure also illustrates an example of the location of fluorescent beads microinjected into the caudal NTS. 


\section{Discussion}

This study shows for the first time that ACh microinjected into the caudal NTS causes strong depressant effects on the cough reflex through the activation of mAChRs. Present findings not only confirm that the caudal NTS is one of the most important sites involved in the modulation of the cough reflex in the rabbit, but also extend our previous results showing that the central mechanisms subserving nociception and cough share similar features (for review see Mutolo, 2017).

We have fully discussed in our previous reports the reliability of microinjection procedures, the spread of the injectate and the localization of injection sites that were selected by using stereotaxic coordinates according to the atlas of Meessen and Olszewski (1949) and confirmed by the histological control (Mutolo et al., 2007, 2008, 2009, 2012, 2013, 2014; Cinelli et al., 2013, 2016). The absence of changes in the ongoing respiratory activity and especially in cough reflex responses following drug microinjections at sites sufficiently far from the responsive sites $(>0.8 \mathrm{~mm})$ as well as following vehicle microinjections into the responsive sites of the caudal NTS supports the specificity of drug-induced effects. The distance of control microinjections from the responsive sites derives from previous observations on the spread of the injectate (see e.g. Nicholson, 1985; Lipski et al., 1988; Mutolo et al., 2002a, 2005; Bongianni et al., 2008, 2010; Sykova and Nicholson, 2008). Given the very short lasting effects of ACh due not only to diffusion, but especially to acetylcholinesterase-induced degradation, we injected in combination $10 \mathrm{mM}$ ACh and $5 \mathrm{mM}$ physostigmine.

ACh-induced changes in respiratory frequency could be of interest. They may reveal an important mechanism of respiratory modulation at the caudal NTS level. ACh-induced increases in respiratory frequency within this region have been also reported by Furuya et al. (2014). Changes in respiratory timing are typically associated with the function of a rhythm-generating mechanism (Von Euler, 1986; Feldman and Del Negro, 2006). It seems plausible that neurons in the caudal NTS are embedded in a ponto-medullary circuit implicated in the control of the respiratory timing (Budzinska et al., 1985a; Von Euler, 1986; Bianchi et al., 1995). On the other hand, it has been recently proposed that the NTS region has an important role in the neural control of breathing (Bautista and Dutschmann, 2014; Jones et al., 2015). Accordingly, it has also been reported that respiratory neurons of the caudal NTS project to the inspiratory neurons located in the preBötzinger complex, the recognized central pattern generator of inspiratory activity, as well as to the rostral respiratory portion of the ventral respiratory group (Alheid et al., 2011) and to the pons (Takakura et al., 2006; Song et al., 2011). All these medullary regions are involved in the regulation of respiratory frequency and probably in the respiratory responses to the peripheral chemoreceptor stimulation (see also Zoccal et al., 2014). ACh microinjections into the caudal NTS could directly or indirectly activate this circuitry and promote tachypnea. In addition, increases in respiratory frequency were accompanied by strong reductions or even complete inhibition of abdominal muscle activity, in agreement with previous studies in the cat showing that the caudal NTS has a clear role in the modulation of the expiratory motor output (Budzinska et al., 1985b). In fact, functional ablation of this area by focal cooling causes obvious increases in rhythmic expiratory activity. In our study, changes in respiratory frequency were relatively transient and disappeared within $5 \mathrm{~min}$ and were absent at the time when cough-suppressant effects were observed, thus suggesting that these two types of ACh-induced responses were subserved by different neural mechanisms. However, the observed depression in expiratory activity usually persisted and could be related to cough-suppressant effects. It is worth mentioning that ACh microinjections into the caudal NTS were less effective in reducing citric acid-induced cough. This outcome could possibly be related to a higher number of recruited acid-sensing receptors and to their deeper localization in the airways, as well as to their well-known association with the generation of tachypneic responses following cough bouts (Sant'Ambrogio and Widdicombe, 2001;
Mutolo et al., 2009).

As already mentioned, present results are in keeping with the proposal of similarities between neural mechanisms underlying nociception and cough. For instance, there is a large body of evidence pointing to the importance of muscarinic signaling in pain control at the level of the spinal dorsal horns. In particular, ACh receptors profoundly regulate nociceptive transmission in the spinal cord via pre- and postsynaptic mechanisms and the direct activation of mAChRs reduces pain in rodents and humans, while their inhibition induces hypersensitivity (for review see Naser and Kuner, 2017).

An important issue is the source of cholinergic inputs to the caudal NTS. A functional cholinergic system has been described in the NTS region as well as a possible role of local cholinergic interneurons modulated by vagal afferent signals. While primary afferent fibers of the solitary tract use glutamate as the primary neurotransmitter, they could activate cholinergic interneurons (Kobayashi et al., 1978; Helke et al., 1983; Ruggiero et al., 1990; Maley, 1996; Shihara et al., 1999; Furuya et al., 2014; Zoccal et al., 2014). Furthermore, it has also been suggested that in addition to glutamate other neurotransmitters, including ACh, may contribute to the neurotransmission of cardiorespiratory signals in the NTS (Criscione et al., 1983; Andresen and Kunze, 1994; Tsukamoto et al., 1994; Machado, 2001; Machado and Bonagamba, 2005; Braga and Machado, 2006; Abdala et al., 2006; da Silva et al., 2008; Furuya et al., 2014; Zoccal et al., 2014). Cholinergic axons may also derive from the dorsal motor vagal nucleus and the nucleus ambiguus (Farkas et al., 1997). In addition, there are cholinergic projections to the brainstem from the ponto-mesencephalic tegmental cholinergic complex. However, their role in the modulation of arterial blood pressure and respiration within the NTS is not clear (Woolf and Butcher, 1989; Woolf, 1991). Further studies are needed to assess the source of ACh for the NTS and to disclose details on synaptic cholinergic mechanisms. In this context, it can be recalled that ACh microinjected into the caudal NTS of the rat causes increases in respiratory frequency through both mAChRs and nAChRs (Furuya et al., 2014). These results are in partial agreement with present findings and the discrepancy may be related to differences in the animal species employed.

The results show that a tonic action of ACh on respiration is lacking. However, it is clear that muscarinic cholinergic mechanisms can modulate both eupneic breathing and the cough reflex. When these mechanisms are brought into action is obscure and only tentative proposals can be advanced. ACh in the caudal NTS may facilitate respiratory responses to peripheral chemoreflex activation, in agreement with previous findings in the rat (Furuya et al., 2014; Zoccal et al., 2014). In addition, not only afferent inputs from chemoreceptors, but also from pulmonary rapidly adapting receptors and C-fibers, that are well known to be involved in tachypneic reflex responses (Sant'Ambrogio and Widdicombe, 2001), converge onto caudal NTS neurons (e.g. Machado, 2001; Kubin et al., 2006). Finally, somatosensory afferent signals, including those conveyed by nociceptive afferents, reach the caudal NTS relayed via the dorsal horn neurons (e.g. Kalia et al., 1981; Craig, 1995; Boscan et al., 2002; see Potts and Waldrop, 2005 for further Refs.). Cardiorespiratory changes and in particular tachypnea induced by somatic afferent stimulation (Duranti et al., 1991 also for further Refs.) may be mediated by the caudal NTS and its functional cholinergic system. In this context, it seems also relevant to mention that cough sensitivity is downregulated by exercise-induced hyperventilation as well as by voluntary isocapnic hyperpnea at similar level (Lavorini et al., 2010).

Present results confirm that the caudal NTS, the main central terminus of bronchopulmonary afferents, has an important role in cough regulation and is a site of action of several neurotransmitters and neuromodulators. However, recent findings in the cat support a similar role for more rostral portions of the NTS (Poliacek et al., 2017a,b; see also Canning and Mori, 2010; Mutolo, 2017), thus suggesting marked species differences in the anatomical and functional organization of 
NTS subnuclei. On the other hand, we have to admit that ACh may also act at the level of the different brainstem neural structures involved in the control of this defensive reflex (Mutolo, 2017), as recently observed by Poliacek et al. (2015) by using nicotine microinjections into the cVRG. The observed absence of an apparent functional involvement of nAChRs following ACh microinjections could be due to barbiturate-inhibition of the nicotinic receptor channels (Morin-Surun et al., 1984; Yost and Dodson, 1993; for review see Arias et al., 2006). However, it seems that this inhibitory mechanism does not contribute very much to conceal nicotinic effects, at least in some animal species (Poliacek et al., 2015).

In conclusion, the results provide substantial evidence that mAChRs modulate both respiration and cough reflex responses. They may also provide hints for further studies not only on details on caudal NTS cholinergic mechanisms, but also on the development of novel antitussive therapeutic strategies. In this context, it should be recalled that available antitussive therapies have limited efficacy and severe side effects that limit their employment in chronic cough, a clinical condition that considerably impairs the quality of life. On the other hand, an impairment of airway defensive reflexes, including cough and swallowing, is a common feature of some neurodegenerative diseases and could lead to aspiration pneumonia and life-threatening conditions (for review see Mutolo, 2017). We believe that not only studies on animal models of chronic cough or neurodegenerative diseases, but also investigations on the basic neural mechanisms underlying the cough reflex in healthy preparations can reveal novel therapeutic approaches for both downregulation and upregulation of the cough reflex.

\section{Funding}

This study was supported by grants from the University of Florence. E.C was supported by a postdoctoral fellowship from the Fondazione Internazionale Menarini.

\section{Disclosures}

No conflict of interest, financial or otherwise, are declared by the Author(s).

\section{Author contributions}

E.C., L.I., F.B., T.P. and D.M. conception and design of research; E.C., L.I., F.B. and D.M. performed experiments; E.C., L.I., F.B. and D.M. analyzed data; E.C., L.I., F.B., T.P. and D.M. interpreted results of experiments; E.C. and L.I. prepared figures; E.C. and D.M. drafted manuscript; E.C., F.B., T.P. and D.M. edited and revised manuscript; E.C., L.I., F.B., T.P. and D.M. approved final version of the manuscript.

\section{References}

Abdala, A.P., Schoorlemmer, G.H., Colombari, E., 2006. Ablation of NK1 receptor bearing neurons in the nucleus of the solitary tract blunts cardiovascular reflexes in awake rats. Brain Res. 1119, 165-173.

Alheid, G.F., Jiao, W., McCrimmon, D.R., 2011. Caudal nuclei of the rat nucleus of the solitary tract differentially innervate respiratory compartments within the ventrolateral medulla. Neuroscience 190, 207-227.

Andresen, M.C., Kunze, D.L., 1994. Nucleus tractus solitarius-gateway to neural circulatory control. Annu. Rev. Physiol. 56, 93-116.

Arias, H.R., Bhumireddy, P., Bouzat, C., 2006. Molecular mechanisms and binding site locations for noncompetitive antagonists of nicotinic acetylcholine receptors. Int. J. Biochem. Cell Biol. 38, 1254-1276.

Bautista, T.G., Dutschmann, M., 2014. Ponto-medullary nuclei involved in the generation of sequential pharyngeal swallowing and concomitant protective laryngeal adduction in situ. J. Physiol. 592, 2605-2623.

Bianchi, A.L., Denavit-Saubie, M., Champagnat, J., 1995. Central control of breathing in mammals: neuronal circuitry, membrane properties, and neurotransmitters. Physiol. Rev. 75, 1-45.

Bongianni, F., Mutolo, D., Fontana, G.A., Pantaleo, T., 1998. Discharge patterns of Bötzinger complex neurons during cough in the cat. Am. J. Physiol. Regul. Integr. Comp. Physiol. 274, R1015-R1024.
Bongianni, F., Mutolo, D., Cinelli, E., Pantaleo, T., 2008. Neurokinin receptor modulation of respiratory activity in the rabbit. Eur. J. Neurosci. 27, 3233-3243.

Bongianni, F., Mutolo, D., Cinelli, E., Pantaleo, T., 2010. Respiratory responses induced by blockades of GABA and glycine receptors within the Bötzinger complex and the pre-Bötzinger complex of the rabbit. Brain Res. 1344, 134-147.

Boscan, P., Kasparov, S., Paton, J.F., 2002. Somatic nociception activates NK1 receptors in the nucleus tractus solitarii to attenuate the baroreceptor cardiac reflex. Eur. J. Neurosci. 16, 907-920.

Boutin, R.C., Alsahafi, Z., Pagliardini, S., 2017. Cholinergic modulation of the parafacial respiratory group. J. Physiol. 595, 1377-1392.

Braga, V.A., Machado, B.H., 2006. Chemoreflex sympathoexcitation was not altered by the antagonism of glutamate receptors in the commissural nucleus tractus solitarii in the working heart-brainstem preparation of rats. Exp. Physiol. 91, 551-559.

Budzinska, K., Von Euler, C., Kao, F.F., Pantaleo, T., Yamamoto, Y., 1985a. Effects of graded focal cold block in the solitary and para-ambigual regions of the medulla in the cat. Acta Physiol. Scand. 124, 317-328.

Budzinska, K., Von Euler, C., Kao, F.F., Pantaleo, T., Yamamoto, Y., 1985b. Release of expiratory muscle activity by graded focal cold block in the medulla. Acta Physiol. Scand. 124, 341-351.

Canning, B.J., Mori, N., 2010. An essential component to brainstem cough gating identified in anesthetized guinea pigs. FASEB J. 24, 3916-3926.

Cinelli, E., Bongianni, F., Pantaleo, T., Mutolo, D., 2013. Suppression of the cough reflex by alpha 2-adrenergic receptor agonists in the rabbit. Physiol. Rep. 1, e00122.

Cinelli, E., Iovino, L., Bongianni, F., Pantaleo, T., Mutolo, D., 2016. GABAA- and glycinemediated inhibitory modulation of the cough reflex in the caudal nucleus tractus solitarii of the rabbit. Am. J. Physiol. Lung Cell Mol. Physiol. 311, L570-L580.

Craig, A.D., 1995. Distribution of brainstem projections from spinal lamina I neurons in the cat and the monkey. J. Comp. Neurol. 361, 225-248.

Criscione, L., Reis, D.J., Talman, W.T., 1983. Cholinergic mechanisms in the nucleus tractus solitarii and cardiovascular regulation in the rat. Eur. J. Pharmacol. 88, 47-55.

da Silva, L.G., Dias, A.C., Furlan, E., Colombari, E., 2008. Nitric oxide modulates the cardiovascular effects elicited by acetylcholine in the NTS of awake rats. Am. J. Physiol. Regul. Integr. Comp. Physiol. 295, R1774-R1781.

Duranti, R., Pantaleo, T., Bellini, F., Bongianni, F., Scano, G., 1991. Respiratory responses induced by the activation of somatic nociceptive afferents in humans. J. Appl Physiol. 71, 2440-2448.

Ernsberger, P., Arango, V., Reis, D.J., 1988. A high density of muscarinic receptors in the rostral ventrolateral medulla of the rat is revealed by correction for autoradiographic efficiency. Neurosci. Lett. 85, 179-186.

Farkas, E., Jansen, A.S., Loewy, A.D., 1997. Periaqueductal gray matter projection to vagal preganglionic neurons and the nucleus tractus solitarius. Brain Res. 764, 257-261.

Feldman, J.L., Del Negro, C.A., 2006. Looking for inspiration: new perspectives on respiratory rhythm. Nat. Rev. Neurosci. 7, 232-242.

Furuya, W.I., Bassi, M., Menani, J.V., Colombari, E., Zoccal, D.B., Colombari, D.S., 2014. Differential modulation of sympathetic and respiratory activities by cholinergic mechanisms in the nucleus of the solitary tract in rats. Exp. Physiol. 99, 743-758.

Furuya, W.I., Colombari, E., Ferguson, A.V., Colombari, D.S., 2017. Effects of acetylcholine and cholinergic antagonists on the activity of nucleus of the solitary tract neurons. Brain Res. 1659, 136-141.

Gestreau, C., Bianchi, A.L., Grelot, L., 1997. Differential brainstem Fos-like immunoreactivity after laryngeal- induced coughing and its reduction by codeine. J. Neurosci. 17, 9340-9352.

Haxhiu, M.A., Mitra, J., van Lunteren, E., Bruce, E.N., Cherniack, N.S., 1984. Hypoglossal and phrenic responses to cholinergic agents applied to ventral medullary surface. Am. J. Physiol. 247, R939-R944.

Helke, C.J., Handelmann, G.E., Jacobowitz, D.M., 1983. Choline acetyltransferase activity in the nucleus tractus solitarius: regulation by the afferent vagus nerve. Brain Res. Bull. 10, 433-436.

Jakus, J., Poliacek, I., Halasova, E., Murin, P., Knocikova, J., Tomori, Z., Bolser, D.C., 2008. Brainstem circuitry of tracheal-bronchial cough: c-fos study in anesthetized cats. Respir. Physiol. Neurobiol. 160, 289-300.

Jones, S.E., Stanic, D., Dutschmann, M., 2015. Dorsal and ventral aspects of the most caudal medullary reticular formation have differential roles in modulation and formation of the respiratory motor pattern in rat. Brain Struct. Funct. 221, 4353-4368.

Kalia, M., Mei, S.S., Kao, F.F., 1981. Central projections from ergoreceptors (C fibers) in muscle involved in cardiopulmonary responses to static exercise. Circ. Res. 48, I48-I62.

Kobayashi, R.M., Palkovits, M., Hruska, R.E., Rothschild, R., Yamamura, H.I., 1978. Regional distribution of muscarinic cholinergic receptors in rat brain. Brain Res. 154 13-23.

Korpáš, J., Tomori, Z., 1979. Cough and Other Respiratory Reflexes. Karger, Basel, Switzerland, pp. 1-356.

Kubin, L., Alheid, G.F., Zuperku, E.J., McCrimmon, D.R., 2006. Central pathways of pulmonary and lower airway vagal afferents. J. Appl. Physiol. 101, 618-627.

Lavorini, F., Fontana, G.A., Chellini, E., Magni, C., Duranti, R., Widdicombe, J., 2010 Desensitization of the cough reflex by exercise and voluntary isocapnic hyperpnea. J. Appl. Physiol. 108, 1061-1068.

Lipski, J., Bellingham, M.C., West, M.J., Pilowsky, P., 1988. Limitations of the technique of pressure microinjection of excitatory amino acids for evoking responses from localized regions of the CNS. J. Neurosci. Methods 26, 169-179.

Machado, B.H., 2001. Neurotransmission of the cardiovascular reflexes in the nucleus tractus solitarii of awake rats. Ann. N. Y. Acad. Sci. 940, 179-196.

Machado, B.H., Bonagamba, L.G., 2005. Antagonism of glutamate receptors in the intermediate and caudal NTS of awake rats produced no changes in the hypertensive 
response to chemoreflex activation. Auton. Neurosci. 117, 25-32.

Maley, B.E., 1996. Immunohistochemical localization of neuropeptides and neurotransmitters in the nucleus solitarius. Chem. Senses 21, 367-376.

Meessen, H., Olszewski, J.A., 1949. A Cytoarchitectonic Atlas of the Rhomboencephalon of the Rabbit. Karger, Basel.

Mifflin, S.W., Spyer, K.M., Withington-Wray, D.J., 1988. Baroreceptor inputs to the nucleus tractus solitarius in the cat: modulation by the hypothalamus. J. Physiol. 399, 369-387.

Mifflin, S.W., 1992. Arterial chemoreceptor input to nucleus tractus solitarius. Am. J. Physiol. 263, R368-R375.

Millan, M.J., 2002. Descending control of pain. Prog. Neurobiol. 66, 355-474.

Morin-Surun, M.P., Champagnat, J., Denavit-Saubie, M., Moyanova, S., 1984. The effects of acetylcholine on bulbar respiratory related neurones. Consequences of anaesthesia by pentobarbital. Naunyn Schmiedebergs Arch. Pharmacol. 325, 205-208.

Mutolo, D., Bongianni, F., Carfi, M., Pantaleo, T., 2002a. Respiratory changes induced by kainic acid lesions in rostral ventral respiratory group of rabbits. Am. J. Physiol. Regul. Integr. Comp. Physiol. 283, R227-R242.

Mutolo, D., Bongianni, F., Pantaleo, T., 2002b. Effects of lignocaine blockades and kainic acid lesions in the Bötzinger complex on spontaneous expiratory activity and cough reflex responses in the rabbit. Neurosci. Lett. 332, 175-179.

Mutolo, D., Bongianni, F., Nardone, F., Pantaleo, T., 2005. Respiratory responses evoked by blockades of ionotropic glutamate receptors within the Bötzinger complex and the pre-Bötzinger complex of the rabbit. Eur. J. Neurosci. 21, 122-134.

Mutolo, D., Bongianni, F., Fontana, G.A., Pantaleo, T., 2007. The role of excitatory amino acids and substance $\mathrm{P}$ in the mediation of the cough reflex within the nucleus tractus solitarii of the rabbit. Brain Res. Bull. 74, 284-293.

Mutolo, D., Bongianni, F., Cinelli, E., Fontana, G.A., Pantaleo, T., 2008. Modulation of the cough reflex by antitussive agents within the caudal aspect of the nucleus tractus solitarii in the rabbit. Am. J. Physiol. Regul. Integr. Comp. Physiol. 295, R243-R251.

Mutolo, D., Bongianni, F., Cinelli, E., Pantaleo, T., 2009. Role of excitatory amino acids in the mediation of tracheobronchial cough induced by citric acid inhalation in the rabbit. Brain Res. Bull. 80, 22-29.

Mutolo, D., Bongianni, F., Cinelli, E., Giovannini, M.G., Pantaleo, T., 2012. Suppression of the cough reflex by inhibition of ERK1/2 activation in the caudal nucleus tractus solitarii of the rabbit. Am. J. Physiol. Regul. Integr. Comp. Physiol. 302, R976-R983.

Mutolo, D., Cinelli, E., Bongianni, F., Evangelista, S., Pantaleo, T., 2013. Comparison between the effects of lisinopril and losartan on the cougn reflex in anesthetized and awake rabbits. J. Physiol. Pharmacol. 64, 201-210.

Mutolo, D., Cinelli, E., Bongianni, F., Pantaleo, T., 2014. Inhibitory control of the cough reflex by galanin receptors in the caudal nucleus tractus solitarii of the rabbit. Am. J. Physiol. Regul. Integr. Comp. Physiol. 307, R1358-R1367.

Mutolo, D., 2017. Brainstem mechanisms underlying the cough reflex and its regulation. Respir. Physiol. Neurobiol. 243, 60-76.

Naser, P.V., Kuner, R., 2017. Molecular, cellular and circuit basis of cholinergic modulation of pain. Neuroscience 30625. http://dx.doi.org/10.1016/j.neuroscience. 2017.08.049. [Epubaheadofprint] pii: S0306-4522(17).

Nicholson, C., 1985. Diffusion from an injected volume of a substance in brain tissue with arbitrary volume fraction and tortuosity. Brain Res. 333, 325-329.

Poliacek, I., Jakuš, J., Stránsky, A., Baráni, H., Halašová, E., Tomori, Z., 2004. Cough, expiration and aspiration reflexes following kainic acid lesions to the pontine respiratory group in anesthetized cats. Physiol. Res. 53, 155-163.

Poliacek, I., Stransky, A., Szereda-Przestaszewska, M., Jakus, J., Barani, H., Tomori, Z., Halasova, E., 2005. Cough and laryngeal muscle discharges in brainstem lesioned anaesthetized cats. Physiol. Res. 54, 645-654.

Poliacek, I., Corrie, L.W., Wang, C., Rose, M.J., Bolser, D.C., 2007. Microinjection of DLH into the region of the caudal ventral respiratory column in the cat: evidence for an endogenous cough-suppressant mechanism. J. Appl. Physiol. 102, 1014-1021.

Poliacek, I., Wang, C., Corrie, L.W., Rose, M.J., Bolser, D.C., 2010. Microinjection of codeine into the region of the caudal ventral respiratory column suppresses cough in anesthetized cats. J. Appl. Physiol. 108, 858-865.

Poliacek, I., Morris, K.F., Lindsey, B.G., Segers, L.S., Rose, M.J., Corrie, L.W., Wang, C., Pitts, T.E., Davenport, P.W., Bolser, D.C., 2011. Blood pressure changes alter tracheobronchial cough: computational model of the respiratory-cough network and in vivo experiments in anesthetized cats. J. Appl. Physiol. 111, 861-873.

Poliacek, I., Jakus, J., Simera, M., Veternik, M., Plevkova, J., 2014. Control of coughing by medullary raphe. Prog. Brain Res. 212, 277-295.

Poliacek, I., Rose, M.J., Pitts, T.E., Mortensen, A., Corrie, L.W., Davenport, P.W., Bolser, D.C., 2015. Central administration of nicotine suppresses tracheobronchial cough in anesthetized cats. J. Appl. Physiol. 118, 265-272.
Poliacek, I., Pitts, T., Rose, M.J., Davenport, P.W., Simera, M., Veternik, M., Kotmanova, Z., Bolser, D.C., 2017a. Microinjection of kynurenic acid in the rostral nucleus of the tractus solitarius disrupts spatiotemporal aspects of mechanically induced tracheobronchial cough. J. Neurophysiol. 117, 2179-2187.

Poliacek, I., Simera, M., Veternik, M., Kotmanova, Z., Bolser, D.C., Machac, P., Jakus, J. 2017b. Role of the dorsomedial medulla in suppression of cough by codeine in cats. Respir. Physiol. Neurobiol. 246, 59-66.

Potts, J.T., Waldrop, T.G., 2005. Discharge patterns of somatosensitive neurons in the nucleus tractus solitarius of the cat. Neuroscience 132, 1123-1134.

Ruggiero, D.A., Giuliano, R., Anwar, M., Stornetta, R., Reis, D.J., 1990. Anatomical substrates of cholinergic-autonomic regulation in the rat. J. Comp. Neurol. 292, 1-53.

Sant'Ambrogio, G., Widdicombe, J., 2001. Reflexes from airway rapidly adapting receptors. Respir. Physiol. 125, 33-45.

Shannon, R., Baekey, D.M., Morris, K.F., Nuding, S.C., Segers, L.S., Lindsey, B.G., 2004. Production of reflex cough by brainstem respiratory networks. Pulm. Pharmacol. Ther. 17, 369-376.

Shao, X.M., Feldman, J.L., 2000. Acetylcholine modulates respiratory pattern: effects mediated by M3-like receptors in preBötzinger complex inspiratory neurons. J. Neurophysiol. 83, 1243-1252.

Shao, X.M., Feldman, J.L., 2001. Mechanisms underlying regulation of respiratory pattern by nicotine in preBötzinger complex. J. Neurophysiol. 85, 2461-2467.

Shao, X.M., Feldman, J.L., 2002. Pharmacology of nicotinic receptors in preBötzinger complex that mediate modulation of respiratory pattern. J. Neurophysiol. 88, 1851-1858.

Shao, X.M., Feldman, J.L., 2009. Central cholinergic regulation of respiration: nicotinic receptors. Acta Pharmacol. Sin. 30, 761-770.

Shao, X.M., Tan, W., Xiu, J., Puskar, N., Fonck, C., Lester, H.A., Feldman, J.L., 2008. Alpha4* nicotinic receptors in preBötzinger complex mediate cholinergic/nicotinic modulation of respiratory rhythm. J. Neurosci. 28, 519-528.

Shek, J.W., Wen, G.Y., Wisniewski, H.M., 1986. Atlas of the Rabbit Brain and Spinal Cord. Karger, Basel.

Shihara, M., Hori, N., Hirooka, Y., Eshima, K., Akaike, N., Takeshita, A., 1999. Cholinergic systems in the nucleus of the solitary tract of rats. Am. J. Physiol. 276, R1141-R1148.

Simera, M., Poliacek, I., Veternik, M., Dobrolubov, B., Cibulka, M., Barani, H., Visnovcova, N., Jakus, J., 2013. Differential effects of kainic acid lesions in medullary raphe on cough and sneeze in anesthetized rabbits. Adv. Exp. Med. Biol. 788, 39-45.

Song, G., Xu, H., Wang, H., Macdonald, S.M., Poon, C.S., 2011. Hypoxia-excited neurons in NTS send axonal projections to Kölliker-Fuse/parabrachial complex in dorsolateral pons. Neuroscience 175, 145-153.

Sykova, E., Nicholson, C., 2008. Diffusion in brain extracellular space. Physiol. Rev. 88, 1277-1340.

Takakura, A.C., Moreira, T.S., Colombari, E., West, G.H., Stornetta, R.L., Guyenet, P.G., 2006. Peripheral chemoreceptor inputs to retrotrapezoid nucleus (RTN) CO2-sensitive neurons in rats. J. Physiol. 572, 503-523.

Tatar, M., Hanacek, J., Widdicombe, J., 2008. The expiration reflex from the trachea and bronchi. Eur. Respir. J. 31, 385-390.

Tsukamoto, K., Yin, M., Sved, A.F., 1994. Effect of atropine injected into the nucleus tractus solitarius on the regulation of blood pressure. Brain Res. 648, 9-15.

Von Euler, C., 1986. Brain stem mechanisms for generation and control of breathing pattern. In: Cherniack, N.S., Widdicombe, J.G. (Eds.), Handbook of Physiology. The Respiratory System. Control of Breathing. American Physiological Society, Bethesda, MA, pp. 1-67.

Widdicombe, J., Fontana, G., 2006. Cough: what's in a name? Eur. Respir. J. 28, 10-15.

Woolf, N.J., Butcher, L.L., 1989. Cholinergic systems in the rat brain: IV. Descending projections of the pontomesencephalic tegmentum. Brain Res. Bull. 23, 519-540.

Woolf, N.J., 1991. Cholinergic systems in mammalian brain and spinal cord. Prog. Neurobiol. 37, 475-524.

Yan, Y.Y., Li, C.Y., Zhou, L., Ao, L.Y., Fang, W.R., Li, Y.M., 2017. Research progress of mechanisms and drug therapy for neuropathic pain. Life Sci. 190, 68-77.

Yost, C.S., Dodson, B.A., 1993. Inhibition of the nicotinic acetylcholine receptor by barbiturates and by procaine: do they act at different sites? Cell. Mol. Neurobiol. 13, 159-172.

Zhang, C., Luo, W., Zhou, P., Sun, T., 2016. Microinjection of acetylcholine into cerebellar fastigial nucleus induces blood depressor response in anesthetized rats. Neurosci. Lett. 629, 79-84.

Zoccal, D.B., Furuya, W.I., Bassi, M., Colombari, D.S., Colombari, E., 2014. The nucleus of the solitary tract and the coordination of respiratory and sympathetic activities. Front. Physiol. 5, 238. 